\title{
GAMBARAN PENGETAHUAN PASIEN GAGAL GINJAL KRONIK TENTANG KEPATUHAN MENJALANI HEMODIALISIS DI RUANG HEMODIALISA RSUP H. ADAM MALIK MEDAN TAHUN 2019
}

\author{
Doni Simatupang, S.Kep, Ns, M.Kep; Febriana Situmorang \\ ABSTRAK
}

Menurut Brunner \& Suddarth 2001, gagal ginjal kronis atau penyakit renal tahap akhir $(E S R D)$ merupakan gangguan fungsi renal yang progresif dan irrevesible dimana kemampuan tubuh gagal mempertahankan metabolisme dan keseimbangan cairan dan elektrolit, yang menyebabkan uremia.

Tujuan penelitian mengetahui gambaran pengetahuan pasien gagal ginjal kronis tentang kepatuhan menjalani hemodialisis di ruang hemodialisa RSUP H. Adam Malik Medan. Metode Penelitian deskriptif dengan desain cross sectional. Teknik pengambilan sampel dengan purposive sampling, dengan 40 responden

Hasil penelitian responden mayoritas usia $46-65$ thn $60 \%$, pengetahuan baik $30 \%$. Pekerjaan mayoritas wiraswasta $42,5 \%$, pendidikan mayoritas SMA 35\% dan mayoritas berpengetahuan baik pada pendidikan Sarjana sebanyak 4 responden $(33,3 \%)$, berdasarkan pekerjaan mayoritas responden berpengetahuan baik pekerja wiraswasta sebanyak 9 responden $(41,7 \%)$, berdasarkan Umur berpengetahuan baik dengan umur 46-65 tahun sebanyak 9 responden $(75,0 \%)$.

Kata kunci: Pasien GGK, Kepatuhan, Hemodialisa

Daftar Pustaka : 24 Bacaan (2000 - 2018)

\begin{abstract}
According to Brunner \& Suddarth 2001, chronic renal failure or end-stage renal disease (ESRD) is a progressive and irrevesible renal function disorder in which the body's ability to maintain metabolism and fluid and electrolyte balance, which causes uremia.

The purpose of this study was to determine the knowledge description of Chronic Kidney Failure Patients About Compliance with Hemodialysis in the hemodialysis room of $\mathrm{H}$. Adam Malik general hospital, Medan. The research method is descriptive with cross sectional design. The sampling technique with purposive sampling with 40 respondents.

The results of the study of the majority of respondents aged $46-65 \mathrm{yr} 60 \%$, good knowledge $30 \%$. Entrepreneur majority $42.5 \%$, high school education majority $35 \%$ and the majority of good knowledge of Bachelor education as many as 4 respondents (33.3\%), based on the work of the majority of respondents with good knowledge entrepreneurial workers as many as 9 respondents $(41.7 \%)$, based on Age, good knowledge with ages $46-65$ years as many as 9 respondents $(75.0 \%)$.
\end{abstract}

Keywords: CRF Patients, Compliance, Hemodialysis

References : 24 Readings (2000 - 2018)

\section{PENDAHULUAN}

\section{Latar Belakang}

Ginjal berfungsi untuk mengatur keseimbangan air dalam tubuh, mengatur konsentrasi garam dalam darah dan keseimbangan asam basah darah serta ekskresi bahan buangan dan kelebihan garam (Pearce 1995 dalam Dewi, 2015). Gagal ginjal kronis atau penyakit renal tahap 
akhir (ESRD) merupakan gangguan fungsi renal yang progresif dan irrevesible dimana kemampuan tubuh gagal mempertahankan metabolisme dan keseimbangan cairan dan elektrolit, yang menyebabkan uremia (Brunner \& Suddarth, 2001 dalam Haryono 2013).

Penyakit Ginjal Kronik didunia saat ini mengalami peningkatan dan menjadi masalah kesehatan serius, hasil penelitian Global Burden of Disease tahun 2010, penyakit ginjal kronik merupakan penyebab kematian peringkat ke 27 di dunia tahun 1990 dan meningkat menjadi urutan ke 18 pada tahun 2010. Lebih dari 2 juta penduduk di dunia mendapatkan perawatan dengan dialisis atau transplantasi ginjal, dan hanya sekitar $10 \%$ yang benar-benar mengalami perawatan tersebut.

Hemodialisa merupakan suatu tindakan terapi pada perawatan penderita gagal ginjal terminal. Tindakan ini sering juga disebut sebagai terapi pengganti karena berfungsi menggantikan sebagian fungsi ginjal. Terapi pengganti yang sering dilakukan adalah hemodialisa dan peritoneal dialisa, diantara kedua jenis tersebut yang menjadi pilihan utama dan merupakan metode perawatan yang umum untuk penderita gagal ginjal adalah hemodialisa (Kartono, dkk. 1992 dalam Dewi 2015).

Pengetahuan sangat erat hubungannya dengan kepatuhan, sehingga diharapkan bahwa pengetahuan yang luas dapat menggambarkan sikap kepatuhan seseorang. Pengetahuan seseorang tentang suatu objek mengandung dua aspek yaitu aspek positif dan aspek negatif, kedua aspek ini yang akan menentukan sikap seseorang, semakin banyak aspek positif dan diketahui maka akan menimbulkan sikap yang semakin baik (Wawan dan Dewi, 2017).

Berdasarkan penelitian (Dewi, 2015) tentang kepatuhan pasien gagal ginjal kronik yang menjalani hemodialisa, didapatkan $70,33 \%$ pasien pada kategori patuh dan masih ada $29,67 \%$ pasien pada kategori tidak patuh. Sedangkan dari aspek pengetahuan pasien gagal ginjal kronik yang menjalani hemodialisa ada $65,67 \%$ pasien pada kategori baik dan ada $30,33 \%$ pasien pada kategori kurang baik.Demikian halnya penelitian yang diakukan oleh (Karundeng, 2015) tentang kepatuhan pasien gagal ginjal kronik yang menjalani hemodialisa, didapatkan ada $78,1 \%$ pasien pada kategori patuh dan ada $21,9 \%$ pasien pada kategori tidak patuh.

Berdasarkan hasil survei yang dilakukan tanggal 23 Januari 2019 di RSUP H. Adam Malik Medan didapatkan bahwa pada tahun 2018 mulai dari bulan Januari sampai Desember diperoleh pasien Gagal Ginjal Kronik sebanyak 368 orang dengan jumlah kunjungan di ruangan Hemodialisa 13.757. Peneliti melakukan survei awal dengan wawancara yang dilakukan oleh peneliti pada tanggal 16 Januari 2019 Pukul 
09.00 Wib di Ruang Hemodialisa RSUP H. Adam Malik Medan, didapatkan bahwa ada 10 pasien gagal ginjal kronik yang menjalani hemodialisa ada 4 pasien mengatakan 2 kali dalam seminggu yang menjalani hemodialisa dan ada 6 pasien mengatakan pernah hanya satu kali menjalani terapi hemodialisa dalam seminggu.

\section{METODE PENELITIAN}

Jenis penelitian ini merupakan penelitian deskriptif dengan desain cross sectional, yaitu rancangan penelitian dengan melakukan pengukuran atau pengamatan pada saat bersamaan (sekali waktu) antara faktor risiko atau paparan dengan penyakit (Aziz Aimul, 2013) yang bertujuan untuk mengetahui gambaran pengetahuan pasien gagal ginjal kronik tentang kepatuhan menjalani hemodialisis di ruang hemodialisa RSUP H Adam Malik Medan tahun 2019.

Adapun populasi pada penelitian ini adalah semua pasien gagal ginjal kronik yg menjalani hemodialisis. Berdasarkan data dari bagian medical record RSUP $\mathrm{H}$. Adam Malik Medan 2018, sebanyak 368 orang. Penelitian ini mengambil sampel dengan pasien gagal ginjal kronis yang menjalani hemodialisis di ruang hemodialisa RSUP. $\mathrm{H}$ Adam Malik Medan, menggunakan rumus Slovin dengan jumlah responden 40 orang.

\section{HASIL DAN PEMBAHASAN}

\section{Hasil Penelitian}

Penelitian mengenai gambaran pengetahuan pasien gagal ginjal kronik tentang kepatuhan menjalani hemodialisis di ruang hemodialisa RSUP $\mathrm{H}$. Adam Malik Medan Tahun 2019 dari tanggal 05 Maret 2019 sampai dengan 10 Mei 2019. Responden pada penelitian ini sebanyak 40 orang. Diperoleh data kemudian diolah dan dianalisa serta disajikan dalam bentuk tabel distribusi frekueensi sebagai berikut:

Tabel 1 Distribusi Frekuensi Pendidikan Pasien Gagal Ginjal Kronik Yang Menjalani Hemodialisis di RSUP H. Adam Malik Medan Tahun 2019

\begin{tabular}{ccc}
\hline Pendidikan & Frekuensi & $\begin{array}{c}\text { Persen(\% } \\
\text { ) }\end{array}$ \\
\hline SD & 6 & 15,0 \\
SMP & 11 & 27,5 \\
SMA & 14 & 35,0 \\
Sarjana & 9 & 22,5 \\
\hline Total & 40 & 100,0 \\
\hline
\end{tabular}

Dari tabel diatas dapat diketahui bahwa responden yang paling banyak berada di pendidikan SMA sebanyak 14 responden $(35,0 \%)$ dan yang paling sedikit berada di pendidikan SD sebanyak 6 responden $(15, \%)$.

Tabel 2 Distribusi Frekuensi Pekerjaan

Pasien Gagal Ginjal Kronik Yang

Menjalani Hemodialisis di RSUP H. Adam Malik Medan Tahun 2019

Pekerjaan Frekuensi Persen(\% 


\begin{tabular}{ccc} 
& & ) \\
\hline Pegawai Negeri & 5 & 12,5 \\
Wiraswasta & 17 & 42,5 \\
Petani & 7 & 17,5 \\
IRT & 7 & 17,5 \\
Tidak bekerja & 4 & 10,0 \\
\hline Total & 40 & 100,0 \\
\hline
\end{tabular}

Dari tabel diatas dapat diketahui bahwa responden yang paling banyak berada di pekerjaan wiraswasta sebanyak 17 responden $(42,5 \%)$ dan paling sedikit berada di pekerjaan tidak bekerja sebanyak 4 responden $(10,0 \%)$.

Tabel 3 Distribusi Frekuensi Umur Pasien Gagal Ginjal Kronik Yang Menjalani Hemodialisis di RSUP H. Adam Malik Medan Tahun 2019

\begin{tabular}{ccc}
\hline Umur & Frekuensi & $\begin{array}{c}\text { Persen } \\
(\%)\end{array}$ \\
\hline 21-45 tahun & 10 & 25,0 \\
46-65 tahun & 24 & 60,0 \\
$>65$ tahun & 6 & 15,0 \\
\hline
\end{tabular}

\begin{tabular}{ccc}
\hline Total & 40 & 100,0 \\
\hline Dari tabel diatas dapat diketahui
\end{tabular}
bahwa responden yang paling banyak berada di umur 46-65 tahun sebanyak 24 responden $(60,0 \%)$ dan paling sedikit berada di umur $>65$ tahun sebanyak 6 responden $(15,0 \%)$.

Tabel 4 Distribusi Frekuensi Pengetahuan Pasien Gagal Ginjal Kronik Yang Menjalani Hemodialisis di RSUP H. Adam Malik Medan Tahun 2019

\begin{tabular}{|c|c|c|}
\hline Pengetahuan & Frekuensi & $\begin{array}{c}\text { Persen } \\
(\%)\end{array}$ \\
\hline Baik 76-100\% & 12 & 30,0 \\
\hline Cukup 56-75\% & 9 & 22,5 \\
\hline Kurang $<56 \%$ & 19 & 47,5 \\
\hline Total & 40 & 100,0 \\
\hline $\begin{array}{l}\text { Dari tabe } \\
\text { bahwa responden } \\
\text { di pengetahuan } \\
\text { responden }(47,5 \% \\
\text { di pengetahuan cu } \\
(22,5 \%) \text {. }\end{array}$ & $\begin{array}{l}\text { diatas da } \\
\text { ang paling } \\
\text { kurang } \\
\text { dan paling } \\
\text { up sebanya }\end{array}$ & $\begin{array}{l}\text { at diketahui } \\
\text { nyak berada } \\
\text { banyak } 19 \\
\text { edikit berada } \\
9 \text { responden }\end{array}$ \\
\hline
\end{tabular}

\section{Tabel 5 Distribusi Frekuensi Pengetahuan Pasien Gagal Ginjal Kronik Tentang} Kepatuhan Menjalani Hemodialisa Berdasarkan Pendidikan di Ruang Hemodialisa RSUP H. Adam Malik Medan Tahun 2019

\begin{tabular}{|c|c|c|c|c|c|c|c|c|}
\hline \multirow{2}{*}{ Pendidikan } & \multicolumn{8}{|c|}{ Pengetahuan } \\
\hline & Baik & $\%$ & Cukup & $\%$ & Kurang & $\%$ & Total & $\%$ \\
\hline SD & 1 & 8,3 & 1 & 11,2 & 4 & 21,1 & 6 & $\begin{array}{c}15 \\
0\end{array}$ \\
\hline SMP & 3 & 25,1 & 2 & $\begin{array}{l}22 \\
2\end{array}$ & 6 & 31,6 & 11 & $\begin{array}{l}27 \\
, 5\end{array}$ \\
\hline
\end{tabular}




\begin{tabular}{crrrrrrrr} 
SMA & 4 & 33,3 & 2 & 22,2 & 8 & 42,1 & 14 & 35,0 \\
Sarjana & 4 & 33,3 & 4 & 44,4 & 1 & 5,2 & 9 & 22,5 \\
\hline & & & & & & & & 100, \\
Total & 12 & 100,0 & 9 & 100,0 & 19 & 100,0 & 40 & 0 \\
\hline
\end{tabular}

Dari tabel diatas dapat diketahui bahwa yang paling banyak pada pengetahuan kurang dengan pendidikan SMA sebanyak 8 responden $(42,1 \%)$ dan yang paling banyak pada pengetahuan baik dengan pendidikan SMA dan sarjana sebanyak 4 responden $(33,3 \%)$.

Tabel 6 Distribusi Frekuensi Pengetahuan Pasien Gagal Ginjal Kronik Tentang Kepatuhan Menjalani Hemodialisa Berdasarkan Pekerjaan di Ruang Hemodialisa RSUP H. Adam Malik Medan Tahun 2019

\begin{tabular}{ccccccccc}
\multirow{2}{*}{ Pekerjaan } & \multicolumn{10}{c}{ Pengetahuan } \\
& Baik & $\%$ & Cukup & $\%$ & Kurang & $\%$ & Total & $\%$ \\
\hline Pegawai Negri & 3 & 25,0 & 1 & 11,1 & 1 & 5,2 & 5 & 12,5 \\
Wiraswasta & 5 & 41,7 & 3 & 33,4 & 9 & 47,4 & 17 & 42,5 \\
Petani & 3 & 25,0 & 1 & 11,1 & 3 & 15,8 & 7 & 17,5 \\
IRT & 1 & 8,3 & 2 & 22,2 & 4 & 21,1 & 7 & 17,5 \\
$\frac{\text { Tidak Bekerja }}{\text { Total }}$ & $\underline{0}$ & $\underline{0,0}$ & $\underline{2}$ & $\underline{22,2}$ & $\underline{2}$ & $\underline{10,5}$ & $\underline{4}$ & $\underline{10,0}$ \\
& 12 & 100,0 & 9 & 100,0 & 19 & 100,0 & 40 & 100, \\
\hline
\end{tabular}

Dari tabel diatas dapat diketahui bahwa yang paling banyak pada pengetahuan kurang dengan pekerjaan wiraswasta sebanyak 9 responden $(47,4 \%)$ dan yang paling banyak pada pengetahuan baik dengan pekerjaan Wiraswasta sebanyak 5 responden $(41,7 \%)$.

Tabel 7 Distribusi Frekuensi Pengetahuan Pasien Gagal Ginjal Kronik Tentang Kepatuhan Menjalani Hemodialisa Berdasarkan Umur di Ruang Hemodialisa RSUP H. Adam Malik Medan Tahun 2019

\begin{tabular}{ccccccccc}
\hline \multirow{2}{*}{ Umur } & \multicolumn{10}{c}{ Pengetahuan } \\
& Baik & $\%$ & Cukup & $\%$ & Kurang & $\%$ & Total & $\%$ \\
\hline 21-45 tahun & 2 & 16,7 & 3 & 33,3 & 5 & 26,3 & 10 & 25,0 \\
46-65 tahun & 9 & 75,0 & 5 & 55,6 & 10 & 11,1 & 24 & 60,0 \\
$>$ >65 tahun & 1 & 8,3 & 1 & 11,1 & 4 & 21,1 & 6 & 15,0 \\
\hline Total & 12 & 100,0 & 9 & 100,0 & 19 & 100,0 & 40 & 0 \\
\hline
\end{tabular}

Dari tabel diatas dapat diketahui bahwa yang paling banyak pada pengetahuan kurang dengan umur 46-65 tahun sebanyak 10 responden $(52,6 \%)$ dan yang paling banyak pada pengetahuan baik dengan umur 46-65 tahun sebanyak 9 responden $(75,0 \%)$. 


\section{Pembahasan}

\section{Analisa Univariat}

a. Pendidikan

Berdasarkan tabel 1 hasil penelitian menunjukkan bahwa responden yang paling banyak berada di pendidikan SMA sebanyak 14 responden (35,0\%). Sama halnya dengan hasil penelitian yang dilakukan oleh Karundeng, 2015 dengan judul "Hubungan kepatuhan pasiien gagal ginjal kronik dengan keteraturan tindakan hemodialisa di BLU RSUP Prof Dr. R.D Kandou Manado" didapatkan bahwa mayoritas responden berpendidikan SMA sebanyak 35 responden $(54,7 \%)$, sama halnya juga dengan hasil penelitian yang dilakukan oleh Johansen, 2017 dengan judul "Hubungan pengetahuan pasien ckd yang menjalani hemodialisis tentang diet dengan kepatuhan menjalankan diet ckd di Instalasi Dialisis RSUD Dr. Pirngadi Medan" didapatkan bahwa mayoritas responden berpendidikan SMA sebanyak 28 responden (45,2\%). Pendidikan pasien juga berperan dalam meningkatkan sikap patuh pasien dalam memahami intruksi pengobatan dan pentingnya perawatan, tetapi kepatuhan pada tingkat pendidikan pasien responden lebih banyak ditemukan pada yang berpendidikan menengah dibandingkan yang berpendidikan rendah (Syamsiah, 2011). Pendidikan pada penelitian ini sangat erat kaitannya dengan rata-rata pendidikan responden.

\section{b. Pekerjaan}

Berdasarkan tabel 2 hasil penelitian menujukkan bahwa responden yang paling banyak berada di pekerjaan wiraswasta sebanyak 17 responden (42,5\%). Berbagai jenis pekerjaan akan berpengaruh pada frekuensi dan distribusi penyakit, tanpa disadari bahwa pekerjaan dapat menyebabkan gagal ginjal seperti pekerja kantoran yang duduk terus menerus sehingga menyebabkan terhempitnya saluran ureter pada ginjal. Disamping itu, intensitas aktivitas sehari-hari seperti orang bekerja dipanasan dan pekerja berat yang banyak mengeluarkan keringat lebih mudah terserang dehidrasi, akibat dehidrasi urin menjdi lebih pekat sehingga bisa menyebabkan terjadinya penyakit ginjal (Ana, 2015 dalam Hartini, 2016). Hasil penelitian ini didukung oleh penelitian yang telah dilakukan oleh Karundeng, 2015 dengan judul "Hubungan kepatuhan pasiien gagal ginjal kronik dengan keteraturan tindakan hemodialisa di BLU RSUP Prof Dr. R.D Kandou Manado" didapatkan bahwa mayoritas responden memiliki pekerjaan sebagai wiraswasta sebanyak 28 responden $(43,7 \%)$, sama halnya juga dengan penelitian yang dilakukan oleh Johansen, 2017 didaptkan bahwa mayoritas responden memiliki pekerjaan sebagai wiraswasta 33 responden $(53,2 \%)$ 
c. Umur

Berdasarkan tabel 3 hasil penelitian menunjukkan bahwa responden yang paling banyak berada di umur 46-65 tahunsebanyak 24 responden $(60,0 \%)$. Penurunan fungsi ginjal dalam skala kecil merupakan proses normal bagi setiap manusia seiring dengan bertambahnya usia, usia merupakan faktor resiko terjadinya gagal ginjal kronik. Semakin bertambah usia seseorang maka semakin berkurang fungsi ginjal, secara normal penurunan fungsi ginjal ini telah terjadi pada usia diatas 40 tahun (Sidharta, 2008 dalam Hartini, 2016). Hasil penelitian ini didukung oleh penelitian yang telah dilakukan oleh Karundeng, 2015 dengan judul "Hubungan kepatuhan pasiien gagal ginjal kronik dengan keteraturan tindakan hemodialisa di BLU RSUP Prof Dr. R.D Kandou Manado" didapatkan bahwa mayoritas responden pada umur 46-55 tahun sebanyak 17 responden $(26,6 \%)$.

\section{d. Pengetahuan}

Berdasarkan tabel 4 hasil penelitian menunjukkan bahwa responden yang paling banyak berada di pengetahuan kurang sebanyak 19 responden $(47,5 \%)$ dan paling sedikit berada di pengetahuan cukup sebanyak 9 responden (22,5\%). Pengetahuan merupakan hasil "tahu" dan ini terjadi setelah orang mengadakan penginderaan terhadap suatu objek tertentu. Penginderaan terhadap objek terjadi melalui panca indera manusia yakni penglihatan, pendengaran, penciuman, rasa dan raba dengan sendiri. Pada waktu penginderaan sampai menghasilkan pengetahuan tersebut sangatdipengaruhi oleh intensitas perhatian persepsi terhadap objek. Sebagian besar pengetahuan manusia diperoleh melalui mata dan telinga (Notoatmojo, 2003 dalam Wawan dan Dewi, 2013).

\section{Analisa Bivariat}

a. Pengetahuan berdasarkan Pendidikan Berdasarkan tabel 5 hasil penelitian menunjukkan bahwa responden yang paling banyak pada pengetahuan kurang dengan pendidikan SMA sebanyak 8 responden $(42,1 \%)$ dan yang paling banyak pada pengetahuan baik dengan pendidikan SMA dan Sarjana sebanyak 4 responden $(33,3 \%)$. Pendidikan diperlukan untuk mendapat informasi, misalnya hal-hal yang menunjang kesehatan sehingga dapat meningkatkan kualitas hidup. Pendidikan dapat mempengaruhi seseorang termasuk juga perilaku seseorang akan pola hidup terutama dalam memotivasi. Pada umumnya, semakin tinggi pendidikan seseorang semakin mudah menerima informasi, pengetahuan dipengaruhi oleh faktor pendidikan formal. Pengetahuan sangat erat hubungannya dengan pendidikan, dimana diharapkan bahwa pendidikan yang tinggi maka orang 
tersebut akan semakin luas pula pengetahuannya (Notoatmodjo, 2010 dalam Wawan dan

Dewi, 2013).

\section{b. Pengetahuan Bedasarkan Pekerjaan}

Berdasarkan tabel 6 hasil penelitian menunjukkan bahwa responden yang paling banyak pada pengetahuan kurang dengan pekerjaan wiraswasta sebanyak 9 responden $(47,4 \%)$ dan yang paling banyak pada pengetahuan baik dengan pekerjaan Wiraswasta sebanyak 5 responden $(41,7 \%)$. Pekerjaan juga mempengaruhi status kesehatan, pekerjaan baik dapat memperbaiki tingkat kesehatan dan kesejahteraan pekerja bila dikelola dengan baik, dapat pula memahami intruksi pengobatan dengan lingkungan pekerjaan, dapat menjadikan seseorang memperoleh pengalaman dan pengetahuan secara langsung maupun tidak langsung (Notoatmodjo, 2010). Seseorang yang bekerja cenderung mempunyai pengetahuan yang cukup baik daripada yang tidak bekerja, hal ini disebabkan karena orang di lingkungan kerja merupakan sumber informasi yang dapat menambah pengetahuan seseorang selain media elektronik (Nursalam, 2001 dalam Sumilati \& Soleha 2015). Pada penelitian ini seseorang dengan pekerjaan wiraswasta hampir setengah dari responden bekerja sebagai wiraswasta sebanyak 17 responden $(42,5 \%)$

\section{c. Pengetahuan Berdasarkan Umur}

Berdasarkan tabel 6 hasil penelitian menunjukkan bahwa responden yang paling banyak pada pengetahuan kurang dengan umur $46-65$ tahun sebanyak 10 orang $(52,6 \%)$ dan yang paling banyak pada pengetahuan baik dengan umur 46-65 tahun sebanyak 9 responden $(75,0 \%)$. Semakin bertambah usia seseorang maka pengetahuan mereka bertambah karena pengetahuan bukan hanya berasal dari lingkungan maupun tingkat pendidikan tetapi pengalaman mereka dalam menghadapi realita kehidupan (Nursalam, 2003 dalam Wawan \& Dewi, 2013). Usia sangat berpengaruh terhadap pengetahuan seseorang, karna pada usia yang sangat dewasa akan semakin banyak pengetahuan yang dimiliki dan memiliki motivasi kuat keinginanya untuk sembuh agar penyakit mereka tidak berlanjut ke stadium yang lebih tinggi (Sumilati \& Soleha, 2015). Pada penelitian ini seseorang dengan umur 46-65 tahun, lebih dari setengah sebanyak 24 responden $(60,0 \%)$. Penelitian ini didukung oleh penelitian yang telah dilakukan oleh Gresia Sinaga, 2017 didapatkan bahwa mayoritas pada pengetahuan kurang berumur 46-55 tahun sebanyak 8 responden $(48,2 \%)$. 


\section{KESIMPULAN DAN SARAN}

\section{Kesimpulan}

Dari hasil penelitian yang diperoleh dan pengolahan data yang dilakukan oleh peneliti dengan judul Gambaran Pengetahuan Pasien Gagal Ginjal Kronik Tentang Kepatuhan Menjalani Hemodialisis di Ruang Hemodialisa RSUP H. Adam Malik Tahun 2019. Maka dapat disimpulkan sebagai berikut:

1. Pengetahuan Pasien Gagal Ginjal Kronik Tentang Kepatuhan Menjalani Hemodialisis di Ruang Hemodialisa RSUP H. Adam Malik Tahun 2019 mayoritas berpengetahuan kurang.

2. Pengetahuan Pasien Gagal Ginjal Kronik Tentang Kepatuhan Menjalani Hemodialisis di Ruang Hemodialisa RSUP H. Adam Malik Tahun 2019 berdasarkan pendidikan mayoritas responden berpengetahuan kurang pada pendidikan SMA.

3. Pengetahuan Pasien Gagal Ginjal Kronik Tentang Kepatuhan Menjalani Hemodialisis di Ruang Hemodialisa RSUP H. Adam Malik Tahun 2019 berdasarkan pekerjaan mayoritas responden berpengetahuan kurang pada pekerjaan wiraswasta.

4. Pengetahuan Pasien Gagal Ginjal Kronik Tentang Kepatuhan Menjalani Hemodialisis di Ruang Hemodialisa RSUP H. Adam Malik Tahun 2019 berdasarkan umur mayoritas responden berpengetahuan kurang pada umur 4665.

\section{Saran}

Setelah melakukan penelitian Gambaran Pengetahuan Pasien Gagal Ginjal Kronik Tentang Kepatuhan Menjalani Hemodialisis di Ruang Hemodialisa RSUP H. Adam Malik Medan Tahun 2019, maka peneliti menyarankan sebagai berikut:

1. Bagi Pasien

Diharapkan tetap selalu memperhatikan kesehatan, konsumsi makanan yang bernutrisi dan jaga asupan cairan tubuh serta meningkatkan pengetahuan dengan cara ikut serta kedalam kelompokkelompok dilingkungan pekerjaan dan masyarakat untuk berdiskusi mengenai penyakit yang disertai dengan petugas kesehatan. Sehingga mampu menerapkan larangan maupun anjuran yang diberikan petugas kesehatan untuk mengatasi gagal ginjal kronik tersebut bagi pribadi maupun diberikan kepada orang lain.

2. Bagi Rumah Sakit dan Petugas Kesehatan

Disarankan untuk tetap memberikan penyuluhan kesehatan baik untuk individu ataupun keluarga tentang 
kepatuhan menjalani hemodialisis sehingga menjadi dasar berfikir yang baik yang akhirnya pasien serta keluarga lebih mengetahui tentang pentingnya hemodialisis dan selalu menganjurkan serta mengingatkan pasien agar patuh menjalani hemodialisis supaya pasien tetap semangat dalam menjalani hidupnya

3. Bagi Institusi Pendidikan

Diharapkan agar hasil penelitian dapat ditambahkan kedalam kepustakaan hasil kajian tentang pengetahuan pasien gagal ginjal kronik tentang kepatuhan menjalani hemodialisis yang dapat dijadikan sebagai bahan acuan untuk pengembangan penelitian dan kajian ilmiah mahasiswa.

\section{Daftar Pustaka}

Agoes, dkk. 2018. Penyakit di Usia Tua. Jakarta: EGC.

Aimul Aziz. 2013. Metode Penelitian Keperawatan Teknik Analisis Data. Jakarta: Salemba Medika.

Almatsier. 2016. Penuntun Diet. Jakarta: Gramedia Pustaka Utama.

Ana. 2015. 14 Penyebab Gagal Ginjal Akut dan Kronik. http://halosehat.com/penyakitginjal/pen yebab-gagal-ginjal. Diakses pada tanggal 14 Mei 2019.

Brunner \& Suddarth. 2002. Keperawatan Medical Bedah. Jakarta : EGC.
Dewi, Nurma. 2015. Gambaran Tingkat Pengetahuan Pasien Gagal Ginjal Kronik Terhadap Kepatuhan Menjalani Hemodialisa Di Rumah Sakit $\mathrm{MH}$ Thamrin. Jurnal IImiah Kesehatan: Vol.1,No.7. Diakses pada tanggal 18/12/2018.

Harahap, Solihuddin. 2016. Faktor-Faktor Risiko Kejadian Gagal Ginjal Kronik (GGK) DiRuang Hemodialisa (HD) RSUP H. Adam Malik Medan. Diakses pada tanggal 15/01/2019.

Haryono, Rudi. 2013. Keperawatan Medikal Bedah Sistem Perkemihan. Yogyakarta: Andi Offest.

Kammerer. 2007. Adherene in Patients On Dialysis: Strategies for Succes. Nephrology Nursing Journal: Vol.34,No.5, 479-485.

Karundeng, Yanny. 2015. Hubungan Kepatuhan Pasien Gagal Ginjal Kronik Dengan Keteraturan Tindakan Hemodialisa Di BLU RSUP Prof Dr. R.D Kandou Manado. Jurnal Keperawatan: Vol.4,No.1. Diakses pada tanggal 18/12/2018.

Morgan, Lois. 2000. A Decade Review: Methods to Improve Adherence to the Treatment Regimen Among Hemodialysis Patients. Nephrology Nursing Journal: Vol.27, No.3.

Notoatmodjo, Soekidjo. 2012. Metodologi Penelitian Kesehatan. Jakarta: Rineka Cipta.

Panduan Penulisan KTI Jurusan Keperawatan Poltekkes Medan. 2015.

Prabowo dan Pranata. 2017. Buku Ajar asuhan Keperawatan Sistem Perkemihan. Yogyakarta: Nurha Medika. 
Price \& Wilson. 2006. Patofisiologi Konsep Klinis Proses-Proses Penyakit Penerjemah dr. Brahm U. Pendit. Jakarta: EGC.

Riskesdas. 2013. Badan Penelitian dan Pengembangan Kesehatan Kementerian Kesehatan RI.

Rohman. 2007. Faktor-faktor yang Berhubungan Dengan Pemberian Asuhan Spiritual Oleh Perawat di RS Islam Jakarta, Tesis. Jakarta: Universitas Indonesia.

Setiadi. 2013. Konsep dan Praktik Penulisan Riset Keperawatan. Yogyakarta: Graha IImu.

Sidharta. 2008. Neurologi Klinis Dasar. Jakarta: Dian Rakyat.

Smeltzer, Suzanne C dan Brenda G Bare. 2002. Buku Ajar Keperawatan Medical Bedah Edisi 8. Jakarta : EGC.

Sumilati \& Soleha. 2015. Hubungan Tingkat Pengetahuan Dengan Kepatuhan Diet Pada Pasien Gagal Ginjal Kronik Yang Dilakukan Hemodialisis Reguler Di Rumah Sakit Darmo Surabaya. Jurnal IImiah Kesehatan 8.

Suryono dkk. 2001. Buku Ajar IImu Penyakit Dalam Jilid II Edisi 3. Jakarta: Balai Penerbit FKUI.

Syamsiah, N. 2011. Faktor-faktor Yang berhubungan Dengan Kepatuhan Pasie CKD Menjalani Hemodialisa. Tesis tidak dipublikasikan. Program pascasarjana Universitas Indonesia, Jakarta.

Wardani dan Ginting. 2015. Hubungan Pengetahuan dan Kecemasan Klien Gagal Ginjal Kronik Menjalani
Hemodialisa. Jurnal Keperawatan. Diakses pada tanggal 19/12/2018.

WHO. 2003. Adherence long-term therapies. Evidence for action. Diperoleh dari http:// www.emro.who.int/ncd/publicity/adherence.r eport.in.diabetic.patien diakses pada tanggal $21 / 01 / 2019$. 